\title{
Interventional cardiology in Poland in the year 2011. Summary report of the Association of Cardiovascular Interventions of the Polish Cardiac Society
}

\author{
Dariusz Dudek ${ }^{1}$, Jacek Legutko', Zbigniew Siudak', Paweł Maciejewski², Andrzej Ochała ${ }^{3}$, Maciej Karcz', \\ Wojciech Wojakowski ${ }^{3}$, Zbigniew Peruga ${ }^{5}$, Aleksander Araszkiewicz ${ }^{6}$, Tomasz Deptuch ${ }^{4}$, \\ Małgorzata Szkutnik ${ }^{7}$, Maciej Lesiak ${ }^{6}$
}

1Jagiellonian University Medical College, Institute of Cardiology, Krakow, Poland

${ }^{2}$ Grochowski Hospital, Warsaw, Poland

${ }^{3}$ Medical University of Silesia, Katowice, Poland

${ }^{4}$ Institute of Cardiology, Warsaw, Poland

${ }^{5}$ Medical University of Lodz, Poland

6Poznan University of Medical Sciences, Poland

${ }^{7}$ Silesian Center for Heart Diseases, Zabrze, Poland

Postep Kardiol Inter 2012; 8, 2 (28): 102-107 DOI: 10.5114/pwki.2012.29651

Once again in the pages of Progress in Interventional Cardiology we publish a summary of the achievements of Polish interventional cardiology. Data for the year 2011 were collected from the database of the Association of Cardiovascular Interventions of the Polish Cardiac Society (AISN PTK) and annual summary reports from all of the catheterization laboratories in Poland. The dynamic development of percutaneous interventional procedures, but also problems with contracting and the valuation of interventional procedures in the past year, are reflected in the numbers of individual procedures.

An upward trend regarding the number of interventional cardiology procedures observed for many years has been sustained in 2011. This applies to both diagnostic procedures (coronary angiography) and therapeutic - percutaneous coronary interventions ( $\mathrm{PCls}$ ). This was mainly related to the opening of new catheterization laboratories, whose number increased to 137 (an increase of 13 catheterization laboratories during one year).

This figure indicates that currently there are 3.6 interventional cardiology centers for one million inhabitants or in other words that there is one center per approximately 280 thousand inhabitants. Importantly, most of them (114, 83\%) operate in $24 \mathrm{~h}$ hemodynamic shifts admitting patients with acute coronary syndromes (ACS). Most catheterization laboratories regularly sent reports on their activities to the
AISN PTK database (96\% of the cath labs) and all cath labs provided a summary report for the previous year.

A total of 88 laboratories are accredited: 15 laboratories have accreditation class A, 51 class B, and 22 cath labs have the highest class $C$ accreditation. Unfortunately, we must once again state that $36 \%$ of laboratories operate without accreditation of the Polish Cardiac Society, which is an important element of quality and safety control for patients treated with percutaneous interventions in Poland. The number of invasive cardiology centers per 1 million inhabitants in different provinces is presented in Figure 1. There is still inhomogeneity regarding the saturation of different provinces with catheterization laboratories: there are a little more than 2 centers per 1 million inhabitants in the Zachodniopomorskie province, while in the Świętokrzyskie province there are more than 5 centers per 1 million inhabitants.

There are currently 705 physicians performing interventional cardiology procedures registered in the AISN PTK database (increase of 7\% in comparison to the year 2010): 142 performing diagnostic procedures (20\%), 532 independent operators (75\%) and 31 physicians during training. Three hundred and eighty of the 780 physicians performing interventional procedures (54\%) have a specialization in cardiology and 102 are in the process of this specialization. One hundred and fifty-eight physicians have

Corresponding author/Adres do korespondencji:

Prof. Dariusz Dudek MD, PhD, Jagiellonian University Medical College, Institute of Cardiology, 17 Kopernika, 31-501 Krakow, Poland,

e-mail: mcdudek@cyfronet.pl

Praca wpłynęła: 23.05.2012, przyjęta do druku: 28.05.2012. 
a specialization in internal disease (22\%) and only 35 physicians (5\%) performing procedures in the catheterization laboratories do not have any specialization.

In comparison to the year 2010 there was an increase of the number of coronary angiography procedures. In total in the year 2011 there were 197284 of them (increase of 9278 in comparison to the year 2010). The total number of PCls was 109 291, which is over 3500 more than in 2010 (PCl/coronary angiography ratio of 0.55 in comparison to 0.56 in 2010). The rate of increase in the number of coronary angiography procedures and $\mathrm{PCls}$ is smaller than the one observed in previous years. It should be noted that $1 / 3$ of $\mathrm{PCl}$ procedures both in stable angina and in acute coronary syndromes (ACS) are performed through the radial artery.

Dynamics of increase of the number of coronary angiography procedures and $\mathrm{PCl}$ in recent years are presented in Figures 2 and 3. The number of $\mathrm{PCl}$ procedures per 1 million inhabitants places Poland above the European average (2866 PCls/million inhabitants), which certainly is an enormous success for our interventional cardiologists. The number of inhabitants per invasive cardiology center is also among the most favorable in Europe. The number of coronary angiography procedures and $\mathrm{PCl}$ procedures per 1 million inhabitants in different provinces is presented in Figures 4 and 5.

There is still some inhomogeneity regarding the number of procedures per 1 million inhabitants between different provinces. The best situation is in the Śląskie and Lubuskie provinces (approximately $3500 \mathrm{PCI}$ procedures per 1 million inhabitants), while in the Zachodniopomorskie province the number slightly exceeds 2000 procedures per 1 million inhabitants. Interestingly, the number of $\mathrm{PCl}$ procedures in the Świętokrzyskie province remains at the national average despite the highest number of catheterization laboratories per 1 million inhabitants.

It remains undetermined to what extent the difference in the number of procedures is related to the different prevalence of coronary artery disease in various regions of the country or to differences in organization, referral status and indications for procedures used in each center.

Procedures other than coronary angiography (intravascular ultrasound - IVUS, fractional flow reserve - FFR, coronary flow reserve - CFR, optical coherent tomography OCT, biopsy) were performed in approximately 1100 patients (including 605 IVUS procedures). This signifies that such procedures are still rarely performed in Polish catheterization laboratories.

We hope that introduction of IVUS and FFR reimbursement in selected clinical situations (with well-documented benefits for the patient) which began on 1.03.2012 for the first time in Poland will lead to a significant increase in the number of this type of procedures in 2012 and the following years.

This applies to the use of IVUS and FFR for the assessment of clinical significance of borderline stenosis in the

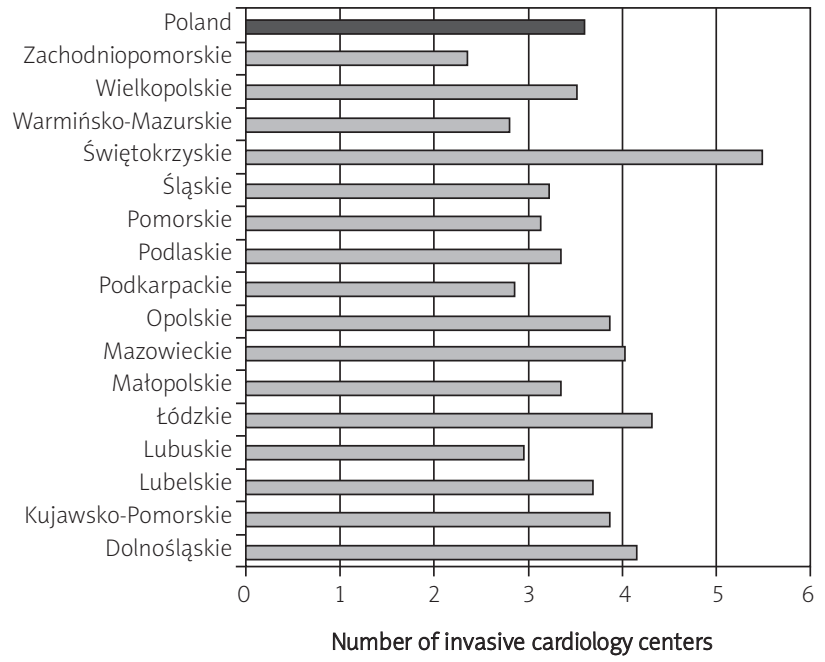

Fig. 1. The number of invasive cardiology centers in Poland per one million inhabitants in different provinces

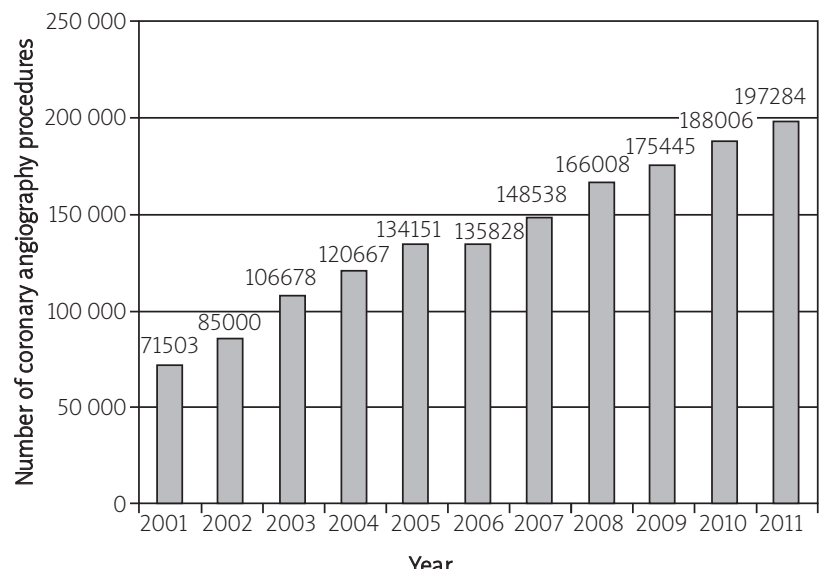

Fig. 2. The number of coronary angiography procedures in Poland in the years 2001-2011

left main stem of the left coronary artery and in the proximal segment of the left anterior descending artery, the use of FFR for the clinical assessment of stenoses in multivessel coronary artery disease and the use of IVUS to optimize stenting of the left main stem of the left coronary artery.

Coronary artery stenting procedures constituted $90 \%$ of all PCl procedures in 2011 (a stable trend since 2009). Once again there is an increase of drug-eluting stent (DES) implantation in comparison to 2010. These stents were implanted in over $38 \%$ of all $\mathrm{PCl}$ procedures (an increase of 11000 procedures in comparison to 2010). However, if only elective procedures (stable angina) are taken into account DES were used in over $52 \%$ of $\mathrm{PCl}$ procedures.

Additionally, an increase in the frequency of DES implantation during $\mathrm{PCl}$ procedures in ACS may be 


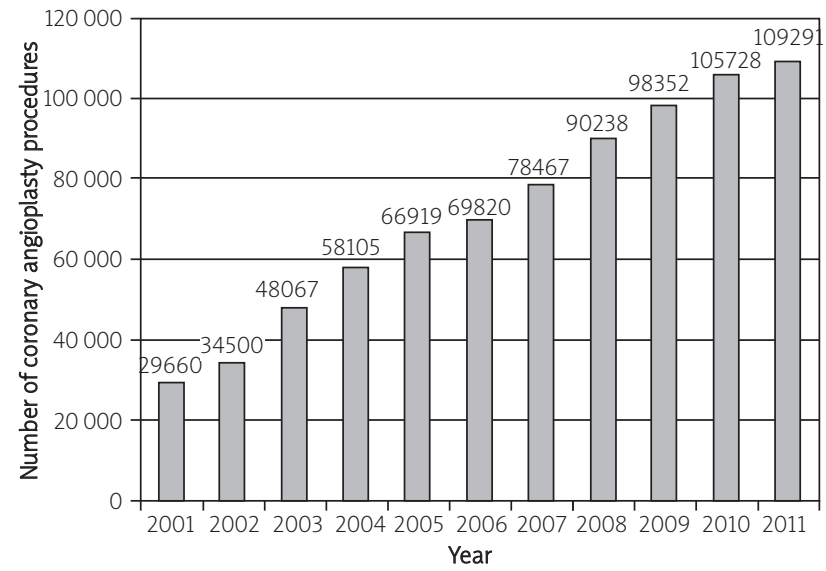

Fig. 3. The number of coronary angioplasty procedures in Poland in the years 2001-2011

observed. Drug-eluting stents were used in $17 \%$ of patients with ST-segment elevation myocardial infarction (STEMI) and in $25 \%$ and $39 \%$ of patients with non-ST-segment elevation myocardial infarction (NSTEMI) and unstable angina, respectively.

Because of the publication of a large amount of data considering higher efficacy and safety of the second and third generation of DES in comparison to the first generation of stents (Cypher, Taxus) further increase in the frequency of DES implantation can be expected. Detailed data regarding stent implantation in the recent years are presented in Figures 6-8.

Data for the last year show further increase of the number of percutaneous coronary interventions in patients with ACS. There were in total 71706 procedures (over 3000 more than in 2010), which represents $66 \%$ of all PCI procedures

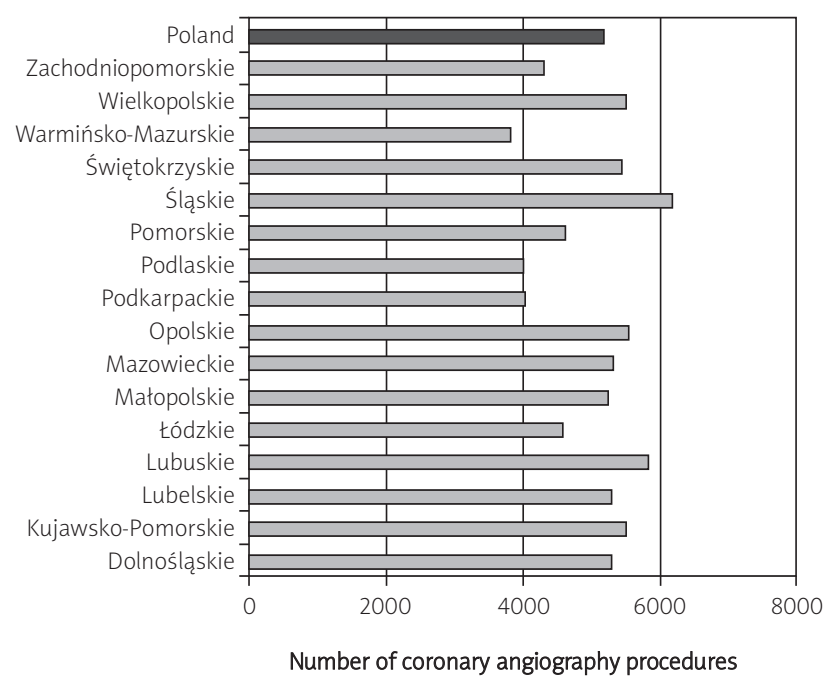

Fig. 4. The number of coronary angiography procedures in Poland in 2011 per million inhabitants in different provinces in Poland. In 2011 there was a modest decrease in the number of invasive procedures in STEMI (from 28595 in 2010 to 28060 last year) and a small increase in the number of procedures in NSTEMI (from 19382 in 2010 to 20997 last year). Our country continues to maintain a leading position in Europe in the organization of interventional treatment of myocardial infarction and for several years has reached and even exceeded the minimum rates established by the European program "Stent for Life". For example, the number of primary PCls in STEMI in Poland is 736 per 1 million inhabitants (with a minimum target number of primary PCls projected by the "Stent for Life" program of 600 per 1 million inhabitants), which is among very good indicators in Europe. There was a significant increase in the number of $\mathrm{PCl}$ procedures for unstable angina in the last year, with 22649 procedures performed last year, which is over 2000 more than in 2010. Detailed data regarding interventional treatment of myocardial infarction in the recent years are presented in Figures 9-11.

Interventional treatment of ACS is inevitably associated with the use of intravenous GP IIb/IIla inhibitors. In 2011 they were used in 16200 patients, which is a result comparable to the year before. Eptifibatide was used in $58 \%$ of cases and abciximab in 41\% of patients (in 2010 this proportion was $50 \%: 50 \%$ ). Details regarding the use of intravenous GP IIb/IIla inhibitors are presented in Table 1. Significant disparities in the use of these drugs between provinces are shown in Figure 12.

This is certainly related to the fact that although the National Health Fund (NFZ) reimburses the use of GP IIb/IIla inhibitors in patients with myocardial infarction, it comes from the pool of elective hospitalizations covered by the contract funding limits. Therefore, centers with low contracts for elective procedures need to make a choice

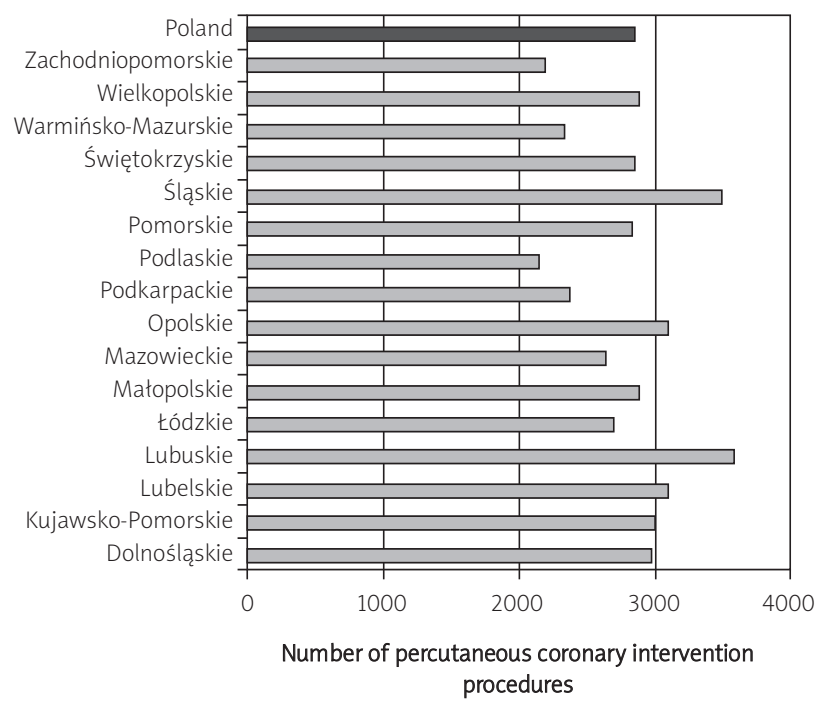

Fig. 5. The number of percutaneous coronary intervention procedures in Poland in 2011 per million inhabitants in different provinces 
between elective coronary angiography, electrotherapy procedures or administration of drugs known to improve prognosis in patients with high-risk myocardial infarction undergoing $\mathrm{PCl}$.

Complications of $\mathrm{PCl}$ procedures (assessed only in the catheterization laboratory) were rare in 2011. Death was reported for $0.77 \%$ of patients undergoing $\mathrm{PCI}$ with a vast majority of cases occurring during coronary angioplasty in the setting of an acute myocardial infarction (2.03\% for STEMI and $0.91 \%$ for NSTEMI). Nonfatal peri-procedural myocardial infarction occurred in $0.59 \%$ of cases and an emergency cardiac surgery due to complications of PC was needed in less than $0.1 \%$ of patients. Peri-procedural stroke occurred in less than $0.1 \%$ of patients.

Non-coronary interventional procedures were performed in cardiology centers in 5446 patients, which signifies a marked increase of this type of interventional cardiology procedures in comparison to the year 2010. In 2011 there were 182 transcatheter aortic valve implantations (TAVI) (funding of these procedures from public resources played a significant role) and 13 pulmonary artery valve implantations. The number of percutaneous closures of patent foramen ovale (PFO) and the number of atrial septal defect (ASD) closures (performed in centers treating adult patients) remained at a similar level in comparison to the year before (in total a little less than 800 procedures). For the first time there was a record in the AISN database about the performance of 45 procedures of left atrial appendage closure in patients with atrial fibrillation and contraindications to chronic anticoagulation.

The number of carotid artery stenting procedures has remained stable for several years, with approximately 900 procedures per year (939 in 2011). Lack of clear rules regarding the reimbursement of these procedures, and controversies raised by neurologists and regarding the guidelines on the treatment of stroke have led to the fact that we do not observe an increase in performance of these procedures in Poland. At the same time, there is an almost 2.5-fold increase in performance of percutaneous interventions on the arteries supplying the lower limbs (both in the supra- and sub-popliteal segments). A detailed list of non-coronary procedures performed in 2011 is presented in Table 2.

In summary, in the year 2011 there were several new invasive cardiology centers opened which supplied the national network of $24 \mathrm{~h}$ hemodynamic shifts for patients with ACS. There was also, once again, an increase in the number of coronary angiography procedures and $\mathrm{PCl}$ and a significant increase of non-coronary interventions (TAVI, PTA).

Priorities of the AISN PTK for the year 2012 include:

1) Collaboration with the Main Board of PTK regarding joint scientific and educational initiatives and health promotion.

2) Collaboration with the Ministry of Health, the National Health Fund and the National Consultant in Cardiology

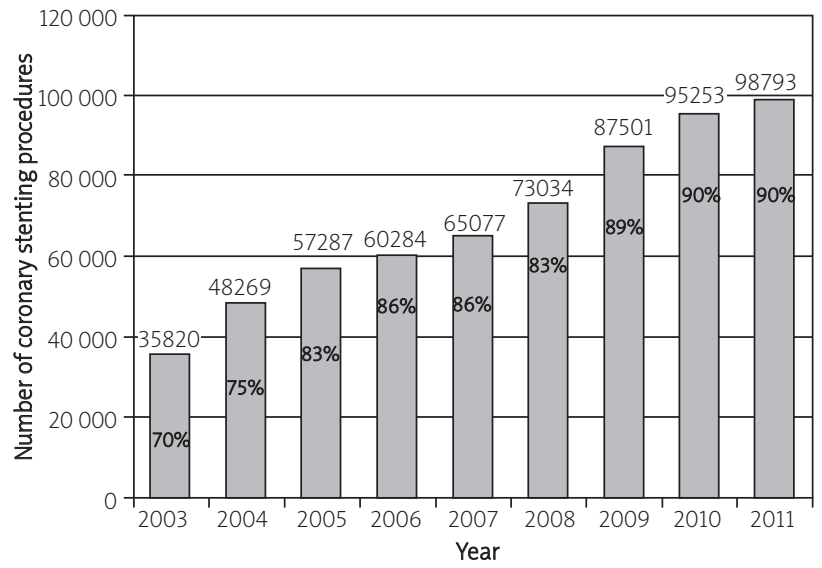

Fig. 6. The number of coronary stenting procedures in Poland in the years 2003-2011

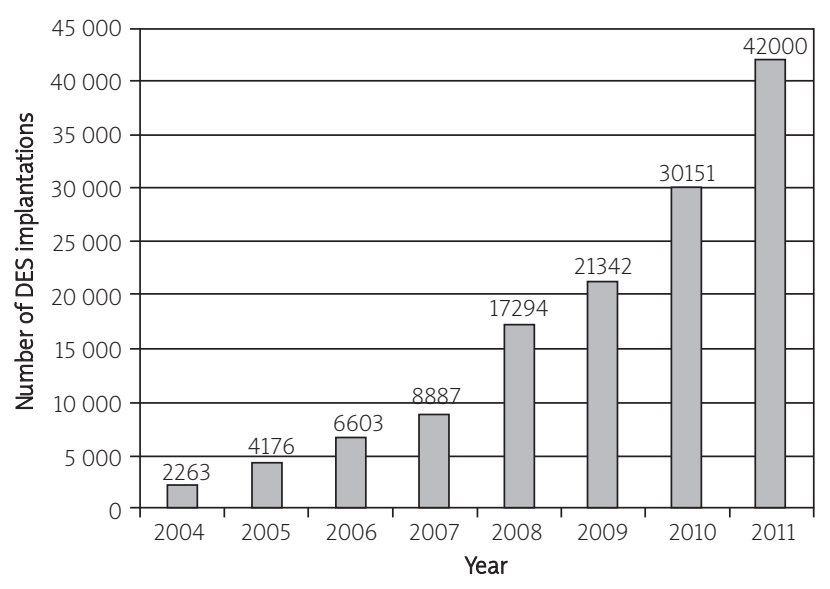

Fig. 7. The number of DES implantations in Poland in the years 2004-2011

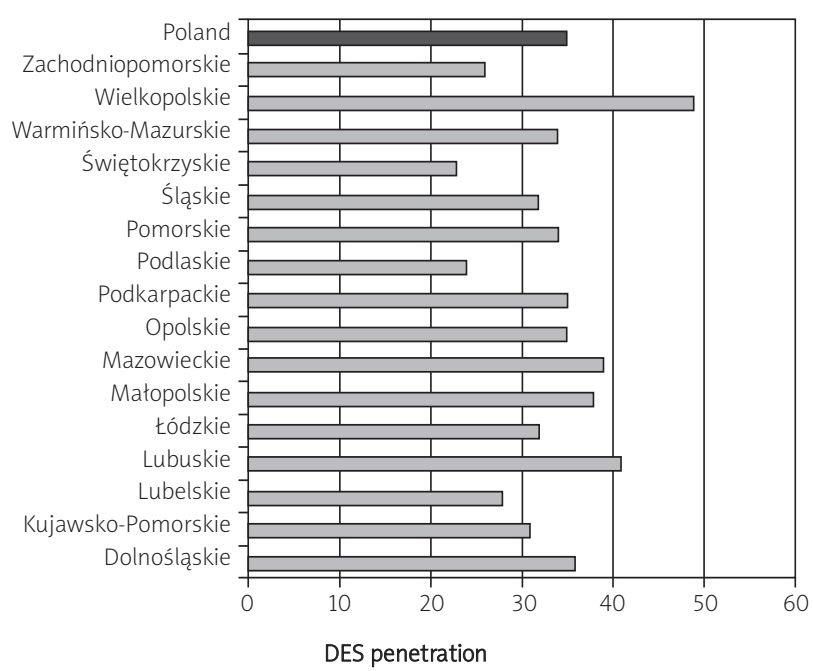

Fig. 8. DES penetration in Poland in 2011 in different provinces 


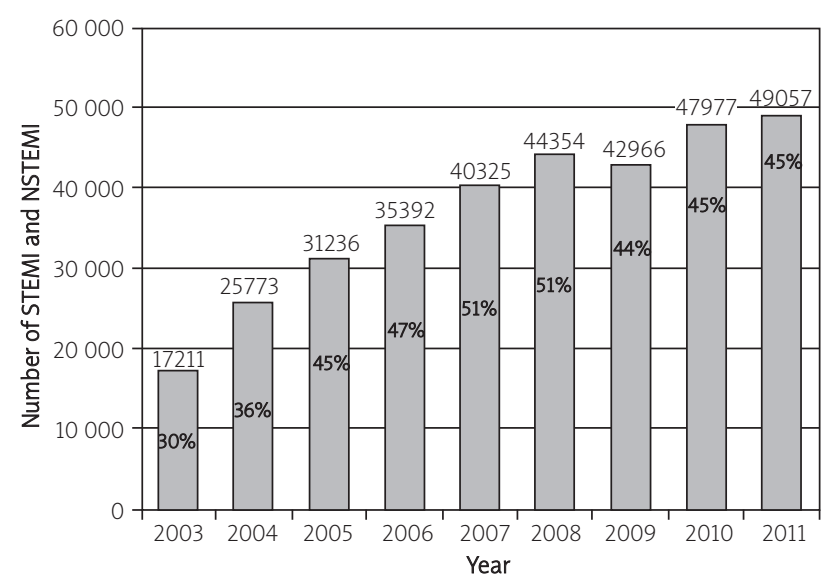

Fig. 9. The number of interventions in acute phase of myocardial infarction in the years 2003-2011 (STEMI and NSTEMI)

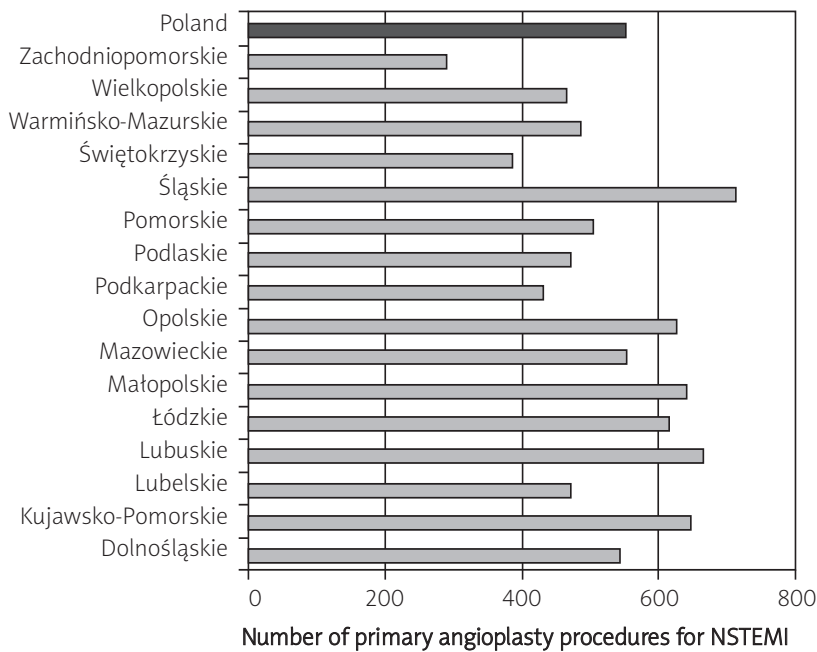

Fig. 10. The number of primary angioplasty procedures for NSTEMI, per million inhabitants in different provinces in 2011

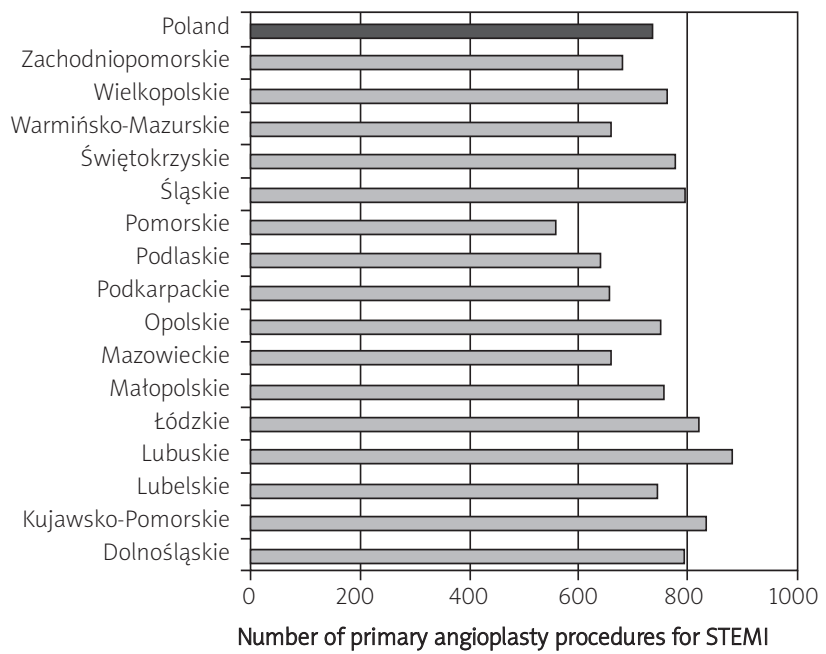

Fig. 11. The number of primary angioplasty procedures for STEMI, per million inhabitants in different provinces in 2011
Table 1. The use of GP IIb/IIla inhibitors in Poland in 2011

\begin{tabular}{lc} 
GP Ilb/llla inhibitor & Number of procedures $(n, \%)$ \\
\hline Abciximab & $6627(41)$ \\
\hline Eptifibatide & $9417(58)$ \\
\hline Tirofiban & $156(1)$ \\
\hline All & 16200
\end{tabular}

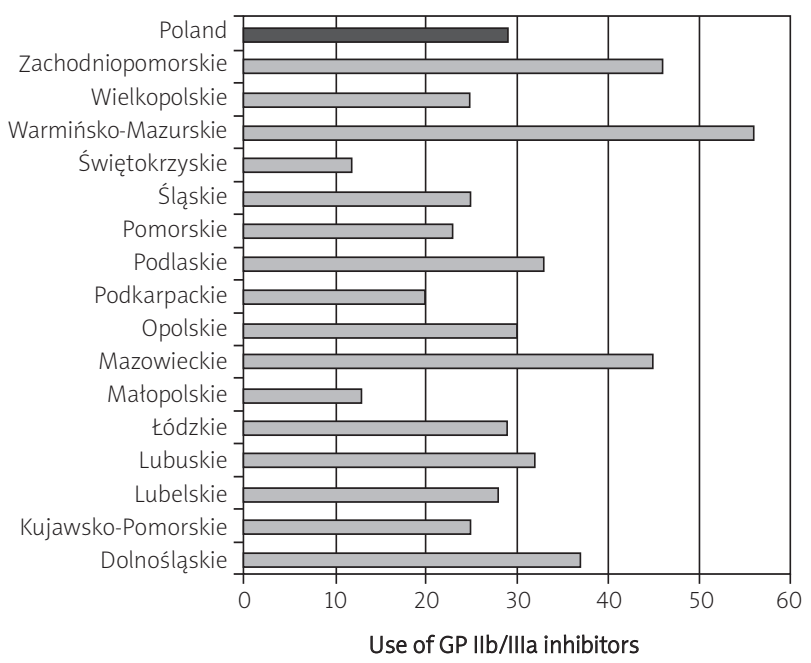

Fig. 12. The use of GP Ilb/IIla inhibitors in patients with ACS in Poland in 2011 in different provinces

Table 2. The number of non-coronary procedures in 2011, performed in cardiac centers for adults in Poland

\begin{tabular}{lc} 
Procedure & Number \\
\hline HOCM ablation & 215 \\
\hline Carotid arteries & 939 \\
\hline Vertebral arteries & 66 \\
\hline Renal arteries & 106 \\
\hline Arteries of the lower limbs above the knee & 2031 \\
\hline Arteries of the lower limbs below the knee & 701 \\
\hline Mitral valvuloplasty & 60 \\
\hline Pulmonary valvuloplasty & 34 \\
\hline Aortic valvuloplasty & 95 \\
\hline PFO closure & 348 \\
\hline ASD closure & 428 \\
\hline VSD closure & 28 \\
\hline PDA closure & 155 \\
\hline LAA closure & 45 \\
\hline TAVI & 182 \\
\hline PAVTI - pulmonary valve & 13 \\
\hline
\end{tabular}


in order to develop reasonable requirements for invasive cardiology centers (inhibition of unjustified rise of personnel and equipment requirements restricting the access of patients to treatment) and to introduce financing of new invasive cardiology procedures.

3) Introduction of uniform certificates for independent invasive cardiology operators and independent diagnosticians.

4) Revision of requirements for accreditation classes for invasive cardiology centers in Poland prepared by PTK.

5) Increase in the number of registered members of AISN PTK and registration of members in the European Association of Percutaneous Cardiovascular Interventions (EAPCI) of the European Cardiac Society (ESC).

6) Continuous collaboration with EAPCI ESC, EuroPCR and TCT.

7) Update of the contact information database of members of the AISN PTK.

8) Measures aimed at streamlining and harmonizing the rules for the conduct of clinical trials in invasive cardiology in Poland.

9) Improvement in reporting from Polish centers and the implementation of quality monitoring regarding compliance with the guidelines of the European Society of Cardiology (ESC) and the assessment of treatment results obtained in different catheterization laboratories in Poland. 